\title{
Cohesive Devices and Academic Writing Quality of Thai Undergraduate Students
}

\author{
Natthapong Chanyoo \\ Faculty of Liberal Arts, Mahidol University, Nakhon Pathom, Thailand
}

\begin{abstract}
The current study aims to investigate (1) common cohesive devices used in the writing development of Thai undergraduate students majoring in English, (2) the frequency of cohesive devices used in the writing of Thai undergraduate students majoring in English, and (3) the relationship between the number and types of cohesive devices and the quality of the writing as rated by writing experts. Thirty junior students majoring in English contributed thirty academic essays as sample texts in the study, with a total number of 16,856 words. Halliday \& Hasan's (1976) taxonomy of cohesion was used as an analytical framework of cohesive devices, while a writing assessment rubric developed by Hogue \& Oshima (2007) was used to determine students' writing quality. His findings revealed four types of cohesive devices frequently used by Thai undergraduate students including reiteration, reference, conjunction, and ellipsis. A one-way ANOVA revealed significant difference numbers of cohesive devices used in the students' writing. In addition, students' writing scores positively correlated with the total number of words used in the writing task, the total number of cohesive devices used, and the number of references.
\end{abstract}

Index Terms - cohesion, cohesive devices, academic writing, Thai English students

\section{INTRODUCTION}

Teaching writing for English language learners is regarded as one of the most challenging tasks for teachers. Academic writing has conventionally been focused on genres such as narrative, expository, descriptive, argumentative and persuasive, to name a few (Connors, 1990). From a narrow viewpoint, writing is considered as a particular kind of verbal production skill where text is manufactured to meet discourse demands. From a broader viewpoint, it is considered a complex, integrated performance that cannot be understood apart from the social and cognitive purposes it serves (Deane et al., 2008). From this broader perspective, writing demands a complex cognitive activity, which involves solving problems and deploying strategies to achieve communication goals (Rao, 2007). For example, writing requires students to concentrate and organize their ideas, and cultivates their ability to summarize, analyze and criticize. Furthermore, writing typically reinforces learning in, thinking in, and reflecting on language as a mode of communication. Writing skills in extended texts at an advanced level, therefore, involve not just the language system but also pose significant challenges to the cognitive systems such as memory and thinking (Kellogg, 2008).

Learning how to compose an effective extended text should be conceived as a task similar to acquiring expertise in a related culturally acquired domain. Learning to write is not merely an extension of acquired spoken language, but it is more similar to learning how to play a musical instrument, which demands twofold competences of both mechanical skills and creative production (Centre for Educational Research and Innovation, 2007). To achieve expertise in writing, the writer must be able to anticipate different ways how the reader might interpret the text and must take this into account while revising it. Students often find composing, especially in languages other than their mother tongue such as when they compose in English, difficult because its process demands their utilization of many cognitive and linguistic strategies. That is to say, to write effective extended texts requires students' mastery in both the target language and thoughts about text-crafting processes. One characteristic of good academic writing is that the text is "making sense". This characteristic is derived through the use of cohesive devices that makes the text logically and semantically consistent as a whole. Textual coherence is thus one of the measures of an effective text.

\section{TeXtuAl COHERENCE}

Textual coherence is a complex aspect of writing that should be approached with caution (Palmer, 1999). Novice learners, when asked to write a composition, could theoretically approach the task by simply drafting some sentences, instead of selecting only those ideas that could be considered relevant for the general structure of their composition (p. 62). Their texts can be well written from a grammatical perspective but without an overall meaning of the text as a whole.

According to Halliday and Hasan (1976), cohesion expresses the continuity that exists between one part of the text and another. It can be divided into two categories. lexical cohesion and grammatical cohesion. Lexical cohesion is realized through the use of reiteration and collocation while grammatical cohesion includes reference, substitution, and ellipsis. Conjunction falls in between two types of cohesion as it sits on the borderline of the grammatical and the lexical. According to Thompson (1996), most conjunctions can be interpreted as both a grammatical and lexical 
semantic unit. Cohesion plays an important role in English language teaching for readers and writers need to be aware of the link that holds chunks of text together, and that contributes to the creation of a text as a unit of meaning (Mahlberg, 2006).

TABLE 1

TYPES OF COHESION

\begin{tabular}{|l|l|l|}
\hline \multirow{2}{*}{ Nature of cohesive relation } & Type of cohesion \\
\cline { 2 - 3 } & Grammatical & Lexical \\
\hline Relatedness of form & Substitution and ellipsis & Lexical collocation \\
\hline Relatedness of reference & Reference & Lexical reiteration \\
\hline Semantic connection & Conjunction \\
\hline
\end{tabular}

\section{COHESIVE DEVICES}

Halliday and Hasan (1976) identify two types of cohesion, namely grammatical and lexical cohesions. Grammatical cohesion involves closed systems. The closed systems are manifest in the options of presence or absence, and the systems of the use of person, number, proximity, and degree of comparison to show the relativeness of the text (p. 303). Grammatical cohesion includes reference, substitution, and ellipsis. However, Thompson (1996) remarks that substitution is a suborder of ellipsis; therefore, substitution is counted as a subtype of the ellipsis. Thompson has offered a good categorization of cohesive devices. Thus, his categorization scheme was used in the current study. Details of the cohesive devices in the study are described as follows:

Reference is a set of grammatical resources that allows the speaker to indicate whether something is being repeated from somewhere earlier in the text. For example, in the following sentences, 'it' refers to the same entity as 'their bedroom', whereas ' $A$ ' in 'A large bed' signals that this is something not mentioned before.

They came into their bedroom. A large bed had been left in it. (Thompson, 1996, p. 180)

Ellipsis is the set of resources by which full repetition of a clause or clause element can be avoided, and by which it can be signaled to readers that they should repeat the wording from a previous clause. There are two types of ellipsis: ellipsis proper and substitution. In ellipsis proper, the element is simply missed out. For example,

How old is he? "Two months."

In the substitution, a linguistic token is put in the place of the wording to be repeated from elsewhere. In the example below, 'so' stands in the place of 'large for five months':

It's large for five months, but not abnormally so.

On the other hand, lexical cohesion involves a kind of choice that is open-ended. The selection of a lexical item is in some way related to once occurring previously. According to Halliday \& Hasan, reiteration and collocation are lexical cohesion subtypes.

Reiteration is the repetition of a lexical item, the occurrence of a synonym, the use of a superordinate (e.g., Jaguarcar), and the use of a general word. In the context of reference, reiteration occurs where the two references have the same referent. Typically, a reiterated lexical item is accompanied by a reference item, usually 'the' or 'a demonstrative adjective'. The complex structure of 'the' plus reiterated lexical item is therefore cohesive by reference. For example,

Boys love playing football. Boys are in the field right now.

Collocation is the association of lexical items that regularly co-occur. Collocation is described as "a word that is in some way associated with another word in the preceding text, because it is a direct repetition of it, or is in some sense synonymous with it, or tends to occur in the same lexical environment, coheres with that word and so contributes to the texture". For example, the adjectives broad and wide are similar in meaning, but occur in very different collocations:

Broad accent, broad agreement, broad daylight but wide appeal, wide area, wide margin (Biber, Conrad, \& Leech, 2002: 18)

Are you fully aware of the implications of your actions? From this example, fully collocates with aware but not deeply aware.

Apart from these two types of cohesion, Halliday and Hasan proposed that conjunction is another type of cohesive device. However, conjunction is on the border line of the grammatical and the lexical. Halliday \& Hasan pointed out in their Cohesion in English (1976) that [the conjunctions] that express conjunctive relations themselves are not tied to any particular sequence in expression. The relationship between any two [or more] sentences does not only occur in a sequential order in the text, but is also realized throughout the grammar of the language (p.227). Mahlberg also affirms that Halliday and Hasan view conjunction as "mainly grammatical, but with a lexical component in it" (2006, p.381). Therefore, the current study will categorize conjunction as a third type of cohesive device. For example,

Leon's apartment complex does not allow dogs over thirty pounds; otherwise, he would have bought the gangly Great Dane puppy playing in the pet store window.

The teaching of coherence and cohesion is relevant to the building of a theoretical approach to writing instruction (Palmer, 1999). As Halliday and Hasan (1976) point out that cohesion refers to relations of meaning that exist within the text (p. 4). From a linguistic perspective, a text is a series of sentences, spoken or written, following one another and forming a unified whole message. A text is best regarded as a semantic unit, a form of a meaning by the realization 
process of sentences (Halliday and Hasan, pp. 1-2). Cohesion is thus expressed through the organization of language. Language can be explained as a multiple coding system comprising three levels of coding: the semantic (meanings), the lexicogrammatical (forms), and their phonological and orthographic realizations. Meanings are realized (coded) as forms, and forms are realized in turn (recoded) as expressions (pp. 5-6). The concept of cohesion, however, is semantic rather than structural in the sense that it functions around the clause rather than within it (Fontaine, 2012, p. 169).

Most EFL teachers are often frustrated by students' incoherent writing in their writing classes, still they cannot find an efficient way to empower students' imagination and set their minds on how to write cohesively. Nevertheless, in order to deliver to students the tools of cohesive devices, teachers need to be informed about those devices that could benefit their students. In other words, teachers need to teach and encourage those EFL students to use accurate devices for more efficient textual compositions.

A number of studies have proved that cohesive devices play a significant role in writing development for L2 or EFL learners (Johnson, 1992; Field \& Oi, 1992; Palmer, 1999, Meisuo, 2000; Crossley \& McNamara, 2010; and Alarcon \& Morales, 2011; Yang \& Sun, 2012). However, whether the number and type of cohesive used in the writing determines writing quality is inconclusive. Some studies found positive relationship between the use of cohesive devices and writing quality. For example, Liu and Braine (2005) examined the number of cohesive devices and the writing quality of 50 argumentative essays written by Chinese EFL students. Their findings revealed that lexical devices contributed the highest percentage of the total number of cohesive devices used in the written texts, followed by references and conjunctions. Statistical analyses show that the composition scores were highly correlated with the number of lexical devices and the total number of cohesive devices used. The study supports a previous study conducted by Palmer (1999) that Spanish English writers preferred to used lexical reiteration in their academic writing. However, Palmer did not investigate the relationship between the type of cohesive devices and the writing quality.

Another study that supports the use of cohesive devices and writing quality was one by Crossley and MacNamara (2010). The study examined how the number of cohesive devices grew along the course of one semester. The researchers found that the number of cohesive devices used in the writing was a good predictor of text organization and overall essay quality as judged by the writing experts. However, they found that the use of coordinating conjunctions and sentence overlap pronouns were negative predictors of the essay quality. This study shows that the frequency of the cohesive devices used in the writing alone cannot be a good predictor of the writing quality. The writing quality depends on the type of cohesive devices used in the writing as well.

Judgment of the L2 writing quality was also supported by the study of Crossley, Kyle, \& McNamara (2016), which investigated the development of local, global, and text cohesion types in L2 writings, and which examined the effects of the cohesion types on judgments of L2 writing quality. The findings suggested that local, global, and text features predicted whether an essay was written at the beginning or at the end of the semester with an accuracy of $71 \%$. Moreover, another $36 \%$ in the variance of the judgment of text quality can be explained by the local, global, and text cohesive features.

In contrast to previous studies that support the number and specific types of cohesive devices in the writing with the writing quality, Alarcon \& Morales (2011) explored cohesive devices used in argumentative essays written by undergraduate students. They used Halliday and Hasan's (1976) taxonomy as their analytical framework. They found that reference made up the highest frequency of the total cohesive devices used in the essays, and accounted for about $91 \%$ of all devices used in the corpus. Conjunction was the second most frequently used device though it occurred ten times less than referencing. Alracon \& Morales, however, did not find a significant relationship between the number of cohesive devices used and the writing quality of the papers. Based on a qualitative analysis, they concluded that the number of cohesive devices alone cannot be claimed to act as a good predictor of the writing quality. Alracon \& Morales, however, recommended that cohesive devices should be introduced to the writers for better writing quality.

Coskun's (2011) compared the English writing of EFL Turkish and Uzbek students. Although their findings supported what has been found in Alarcon \& Morales's study that the use of cohesive devices was not significantly related to the quality of the writing, the study shows differences in that EFL Turkish and Uzbek students preferred to use grammatical devices (such as ellipsis) to the lexical devices, which were commonly found in the previous studies.

Given that previous studies show disagreement between the number of cohesive devices and types of cohesive devices contributing to writing quality, as well as the fact that no such studies have been conducted to investigate whether or not Thai EFL students show similar or different patterns in the use of cohesive devices and writing quality, the current study therefore aims to examine the relationship between cohesive devices and overall writing quality in the academic writing of Thai EFL students. The specific objectives are embedded in these following research questions.

1. What are the common cohesive devices used in the development of the Thai undergraduate students' academic writing?

2. Which cohesive devices are used by the Thai undergraduate students majoring in English in their academic writing? How frequently are they used?

3. Is there a relationship between the use of cohesive devices and the quality of writing?

\section{Methodology}

\section{A. Design}


The current study is based around a quantitative design. Halliday and Hasan's taxonomy (1976) as revised by Thompson (1996) was used as the framework for analysis. The cohesive devices used in academic writing written by Thai undergraduate students majoring in English were analyzed. Regarding writing quality, an essay rubric developed by Hogue \& Oshima (2007) was used in the study because it is a precise rubric and widely adopted as a major writing assessment tool in writing courses for Thai EFL writers.

\section{B. The Corpus}

The corpus consisted of 30 academic essays, with a total word count of 16,856. The essays were written by 30 Thai junior students majoring in English. Student writers provided their responses to the prompt provided by the researcher. The prompt asked about their judgments on readings related to teaching English as a second/foreign language.

\section{Procedure}

The objectives of the study were firstly described to the students. They were asked whether they granted permission for the researcher to use their papers as data sources in the study. The writing samples included only those who consented to contribute their writing for the study. Students had three hours to write their response to the given prompt. No assisting resources in any form were allowed during the writing. Thus, all responses came solely from students without external assistance. After the students finished the writing task, the researcher collected students' writings. Then all writings were typed into the .doc format, strictly following what students wrote. No errors were corrected. All file scripts were converted into a text format (.txt) and graded by the researcher. Regarding the writing quality judgment, the researcher adopted a holistic writing rubric developed by Hogue \& Oshima (2007) to assess students' writings. The maximum score for the writing was 100 . To assure consistency of the grading process, six assignments were randomly selected for inter-rater reliability. The other grader was a native speaker of English, experienced in teaching writing for EFL students. Pearson's correlation coefficient was used to calculate inter-rater agreement between the graders. Peason's correlation coefficient for inter-rater consistency was 0.93 , which was considered highly consistent between the graders. After all writings were graded, a manual annotation was done by the researcher for cohesive devices used in all writings.

\section{Data Analysis}

All cohesive devices, based on a revised version of Halliday and Hasan's categorization, were manually sorted by the researcher. Further, the AntCon program was used to validate the findings. The AntCon program is used to confirm the reliability of the frequency of cohesive devices found in the corpus. Frequency, percentage, mean, and an F-test were used to identify and compare the frequency and types of cohesive devices used in the corpus. Pearson's correlation coefficient was used to determine the frequency of cohesive devices and the writing quality as judged by the writing expert.

\section{FINDINGS}

Students completed their writing in three hours. The writing prompt was about teaching English as a second/foreign language. The students had to write a response to an impromptu question. No assisting resources of any form were allowed during the writing. Thus, all responses were derived solely from students with no assistance from external sources. Demographic data of the corpus is described in Table 3.

TABLE 3

DEMOGRAPHIC DATA OF THE SAMPLE TEXTS

\begin{tabular}{|l|l|}
\hline DEMOGRAPHIC DATA OF THE SAMPLE TEXTS \\
\hline Number of texts & 30 \\
\hline Word counts & 16,856 \\
\hline Average word counts & 561.87 \\
\hline Word count range & $252-2,070$ \\
\hline Word count $S D$ & 199.28 \\
\hline Maximum score & 92 \\
\hline Minimum score & 56 \\
\hline Average score & 74.63 \\
\hline Score $S D$ & 10.66 \\
\hline
\end{tabular}

From Table 3, it can be seen that the texts are diverse in terms of length. The longest text contains 2,070 words, while the shortest one was 252 words. In other words, under a three-hour time limit, students performed differently in writing their responses toward the prompt. The students who wrote the most wrote almost ten times more text than the students who wrote the least. The highest score the students gained from this assignment was 92, while the lowest was 56. The average score was 74.63 , with a standard deviation of 10.66 .

Halliday \& Hasan's revised version of cohesive categories (i.e., ellipsis, reference, collocation, reiteration, and conjunction) was used to determine the common cohesive devices used in the development of the Thai undergraduate writing in English. Table 4 shows the types of cohesive devices used by student writers. 
TABLE 4.

COHESIVE DEVICES USED IN THE SAMPLE TEXTS.

\begin{tabular}{|l|l|l|l|}
\hline Features & $f$ & $\%$ & $S D$ \\
\hline Ellipsis & 62 & 2.25 & 1.38 \\
\hline Reference & 646 & 23.49 & 12.34 \\
\hline Collocation & 0 & 0 & 0 \\
\hline Reiteration & 1,769 & 64.30 & 32.56 \\
\hline Conjunction & 274 & 9.96 & 4.91 \\
\hline Total & 2,751 & 100.00 & \\
\hline
\end{tabular}

Table 4 shows that, of all 30 excerpts written by the students, reiteration was the most frequently used cohesive type in the corpus $(f=1,769$, or $64.30 \%)$, followed by reference $(f=646$, or $23.49 \%)$, and conjunction $(f=2.74$, or $9.96 \%)$.

TABLE 5

\begin{tabular}{l|l|l|l|l|}
\multirow{4}{*}{ MEANS COMPARISON AMONG COHESIVE DEVICES USED IN THE ACADEMIC WRITING } \\
\cline { 2 - 5 } & SS & $\mathrm{df}$ & MS & F \\
\hline Between Groups & 58630.89 & 3 & 19543.63 & $63.130 * * *$ \\
Within Groups & 35911.10 & 116 & 309.58 & \\
Total & 94541.99 & 119 & & \\
\hline \multicolumn{5}{c}{$* * * \mathrm{p}<.001$}
\end{tabular}

A one-way ANOVA was performed to investigate differences for the types of cohesive devices used in the corpus. There was a statistically significant difference among types of cohesive devices as determined by the one-way ANOVA $[\mathrm{F}(3,119, p=.000)]$. An LSD post hoc test revealed that reiteration was used as a cohesive device $(\mathrm{M}=64.30, \mathrm{SD}=$ 32.56) more often than the use of reference $(M=23.49, S D=12.34)$, the use of conjunction $(M=9.96, S D=4.91)$, and the use of ellipsis $(M=2.25, S D=1.38)$, statistically significant at ps <.001. Moreover, references were used more often than conjunctions $(p<.01)$, and ellipsis $(p<.001)$.

TABLE 6

RELATIONSHIP BETWEEN THE FREQUENCY OF COHESIVE DEVICES, WORD COUNT, AND THE QUALITY OF THE WRITING

\begin{tabular}{|l|l|l|l|l|l|l|l|}
\hline & 1 & 2 & 3 & 4 & 5 & 6 & 7 \\
\hline 1. Score & - & $.633^{* *}$ & $.422^{*}$ & .258 & .139 & $.511^{* *}$ & .332 \\
\hline 2. Word count & $.633^{* *}$ & - & $.867 * *$ & $.563^{* *}$ & .215 & $.735^{* *}$ & $.799^{* *}$ \\
\hline $\begin{array}{l}\text { 3. Cohesive } \\
\text { Devices }\end{array}$ & $.422^{*}$ & $.867 * *$ & - & $.544 * *$ & $.366^{*}$ & .771 & $.962^{* *}$ \\
\hline 4. Conjunction & .258 & $.563^{* *}$ & $.544^{* *}$ & - & .124 & $.435^{*}$ & $.414^{*}$ \\
\hline 5. Ellipsis & .139 & .215 & $.366^{*}$ & .124 & - & .202 & .357 \\
\hline 6. Reference & $.511^{* *}$ & $.723^{* *}$ & $.771^{* *}$ & $.435^{*}$ & .202 & - & $.589 * *$ \\
\hline 7. Reiteration & .332 & $.799^{* *}$ & $.962^{* *}$ & $.414^{*}$ & .357 & $.589 * *$ & - \\
\hline
\end{tabular}

To assess the relationship between factors and the writing quality, Pearson's correlation coefficients were performed. The findings revealed a positive relationship between number of words in the writing and writing score $(r=.633$, $p<.01)$, the number of cohesive devices used and the writing score $(r=.422, p<.05)$, and the number of references and the writing score $(r=.511, p<.01)$.

Regarding word counts and the use of cohesive devices, it was found the length of the text positively correlated with overall number of cohesive devices used $(r=.867, p<.01)$. In particular, the length of the writing showed a positive relationship with the number of conjunctions $(r=.563, p<.01)$, references $(r=.771, p<.01)$, and reiterations $(r=.799$, $p<.01)$.

\section{DISCUSSION}

In this section, the researcher will discuss the findings of this study based on the research questions provided earlier.

Regarding the types of cohesive devices that were commonly used by student writers, it was found that Thai English writers preferred to use reiteration, followed by reference, and conjunction.

It is not surprising that reiteration was used the most in students' writings because the use of synonyms or repetition of the words is the easiest tool for student writers to employ in their writing. The writers, especially less competent ones, tend to employ this strategy to convince the reader that the topic they were writing about was well controlled. That is, the progression of the text was still around and stayed focused with the same central idea. The findings were in line with that of Palmer's (1999) findings that non-native English language learners created coherent texts through the use of lexical reiteration. Palmer further suggested that teachers must enhance the teaching of coherence and cohesion in English lesson, especially using reading as examples. This intervention may help learners to link example cohesive devices given in the readings to produce their own written work. The teachers may also provide the student writers a wide variety of examples of cohesive devices so that they could make their texts less monotonous.

Additionally, mental processing explains why students preferred to employ reiteration in their texts. This is may be due to the fact that the lexical item is easier to process. In production, student writers typically have a limited number of lexical items that are ready for them to retrieve for a productive task. For example, reading passages, or listening 
dialogues are tasks that are considered "easier", if compared with speaking or writing tasks. When student writers produce their own texts, they need a set of linguistic devices that is 'online', or ready for them to use concurrently. Student writers mostly demonstrated that they struggled to retrieve their linguistic tools to develop their texts. As a consequence, teachers of productive skills such as writing and speaking must help them possess as many sets of linguistic tools that are ready to use as possible. To provide different sets of cohesive devices such as lexical and grammatical cohesions is among the tools that will be beneficial for the learners to make their texts flow smoothly.

The order of cohesive devices used also suggests the order of acquisition, or degree of difficulty that Thai EFL writers may have perceived at the time they were learning some cohesive devices. Based on the findings, reiteration was the most frequently used device, followed by references, and conjunctions. One possible explanation could be connected to meaning transparency. That is, foreign language learners tend to use the linguistic devices through which they can be most certain that the meaning is exactly the meaning they intended to communicate. Undergraduate Thai students majoring in English might lack the repertoire of vocabulary to restate the topic using other words. Therefore, the level of proficiency also plays a role in how writers at different levels used different proportions of cohesive devices in their writings.

Moving from repetition of the same word, it was obvious that students used a synonym to show links in their text. For example, one student used "a study" for "a research project". Interestingly, however, the use of synonyms is varied on the spectrum showed that some words are "close relative" to the key word, while others are more deviant from the key term. To use a synonym, found in the dictionary without knowing its closeness in terms of the meaning to the key term, will weaken the coherence of the writing. Teachers should raise students' awareness of this matter. Moreover, writing teachers may inform the students that they may read the whole paragraph, or even the whole text to identify whether the text is 'coherent', meaning that when they want to make their text coherent, students cannot only rely on the employment of synonyms. Instead, they need to be certain that they keep the 'central idea' of the text consistent through the use of various cohesive devices.

Conjunction is the third most common cohesive device for the Thai English writers. Conjunctions (typically and and but) are considered as one of the most transparent cohesive devices. Therefore, it is among the popular devices to show coherence in the writing. Conjunction is predominantly used by foreign language writers because most of the learners have limited numbers of linguistic devices in their repertoire to show coherence in their writing. A number of studies in second or foreign language writing found that conjunctions are always overused by second/ foreign language student writers because conjunction is a less mature form of writing to subordination. Also, conjunctions are commonly found in early English L1 acquisition in children. This claim was supported by the studies of Mei (2006) and Chanyoo (2013), who found that second and foreign language writers prefer to use conjunctions to conjoin their text, and thus make the text coherent. The reason why students prefer to use the conjunctions is due to the fact that conjunction carries its literal meaning. The lexical forms of conjunction suggest the meaning so that the students do not need to process, or investigate further for the emotional meaning of the conjunctions (or so called connotation). In other words, conjunction is more transparent in terms of its meaning (e.g., and vs however), as compared to other cohesive devices. Moreover, since conjunction is in between lexical and grammatical cohesions, it is easier for the learners to employ because they do not need to consider whether the conjunction they use to link ideas is at a word, or clausal level. That is to say, the conjunction is additive rather than relational.

The current findings suggest that Thai undergraduate writers preferred to use reiteration and reference in their writing, followed by conjunction. Reiteration is considered as an interclausal semantic device because it is used to connect different parts of the same idea, or repeat the meaning of the previously mentioned word. In contrast, reference and conjunction are considered as interclausal syntactically because they are used to refer to the previously mentioned idea in a clausal or a sentential level. The current findings suggested that undergraduate English major students showed developmental progress in that they were moving from the use of cohesive devices at interclausal semantic (e.g., reiteration) to interclausal syntactic (e.g., reference and conjunction) level. Thus, it is possible to conclude that students were on a developmental course. If a teacher provides more sets of cohesive devices that are ready for them to use, their texts will become more interesting in terms of becoming more diverse and less repetitious.

This acts in contrast with native speaking writers. The English native speakers employed more syntactic ties such as references and conjunction in their texts. Therefore, it is possible to claim that when native speakers of the language produce written products, they tended to employ interclausal syntactic cohesive devices. It would, however, not be wise to claim that the group of students used in this study are native-like writers of English at this time. However, it is promising that students at this proficiency level, produce texts that are somewhat in line with those of native speakers. Palmer's (1999) study explored cohesive devices mostly used by non-native English language students. She found that lexical reiteration is the most used device by the students she observed. She also recommends that the enhancement of the teaching of coherence and cohesion in English lessons, in an attempt to join any theoretical approach to both reading and writing instructions, will help learners to write more effectively.

The findings of the current study were different from those of Coskum's comparative study in the use of cohesive devices between 5th graders in Uzbekistan and Turkey (2011). Her findings suggested that the most frequently used devices were ellipsis, conjunctions, lexical cohesion (reiteration), while reference was rare in the corpus. This incongruity may be due to different thinking processes between Thai and Central Asian/Middle Eastern students. That is, 
nouns are the central focus of the story among Thai students. In order to make their text coherent, reiteration was then preferred as a linkage in the text. In contrast, the Uzbek and Turkish students may process their story basically through the use of references and conjunctions. They probably prefer not to state the link of the story directly through the use of interclausal semantic cues of reiteration or synonym. Rather, the Central Asian/Middle Eastern student writers tended to make connections in the text by interpreting through interclausal syntactic cues such as ellipses or conjunctions. Although differences were found among these L1 backgrounds, two of the top three most frequently used devices in the L2 academic writing referenced here were still references and conjunctions. Again, the concept of meaning transparency somehow plays a role here in that L2 learners tend to predominantly employ the devices with which they know how to convey the exact meaning as they intend. Nonetheless, having access to a small number of lexical devices may impede them from employing various cohesive devices in their writing.

The third point to discuss from the findings is whether there is a relationship between the number of cohesive devices used in the academic writing and the quality of the writing. In the current study, the quality of a student's writing was gleaned from the score they got from the writing holistic rubric score as rated by writing experts. It was found that students who got a higher score for their writing tended to produce a longer text with the use of cohesive devices. Similar findings were found in the study of Liu and Braine (2005), who found that the frequency of cohesive devices used by Chinese students in their academic essays significantly correlated with the quality of writing. This means that a higher frequency of cohesive devices led to higher-rated essay score. In addition, Liu and Braine revealed that among the three cohesive categories, reiteration was the most frequently used, followed by reference items. Conjunctions were the least commonly used device in the corpus.

The current findings are in line with the study of Meisuo (2000) that the use of cohesive devices and writing quality were not interrelated. Nonetheless, Meisuo found that the lexical category (such as reiteration and synonym) had the highest percentage of ties, followed by conjunctions and references. In contrast to Meisuo's study, the current study revealed that a strong connection in the use of cohesive devices and the quality of writing was significant. However, it is noteworthy that, in agreement with Meisuo's, the number of ties, or cohesive devices, alone could not be a reliable indicator of the quality of writing. Further studies of influential factors on the quality of writing should be carefully conducted.

Nevertheless, among the cohesive devices used in the text, the only device that shows a relationship with a higher score is the use of reference. From the findings, it seems clear that when students write their academic texts, they need to employ a number of references as their main cohesive device. Reference mainly refers to the previously mentioned idea at a clausal or sentence level. As suggested by Johnson (1992) reference is a syntactic device that refers to the idea previously mentioned at a clausal or sentential level. Thus, the use of references reflects students' ability to make connections from the previous segment to the current one by using a word that represents the whole idea, instead of matching word-by-word through the use of reiteration. The claim of the contribution of references to higher writing scores is supported by Alarcon \& Morales (2011), who also found that reference had the highest frequency (or 90.67\%) of the total grammatical cohesive devices associated with writing quality, followed by conjunction and ellipsis. Coskun (2011) also supported the claim that that Uzbek and Turkish students' low writing scores were due to limited use of reference and ellipsis; both make the text more coherent. Coskun also adds that incompetent writers tend to use more ellipsis, conjunction, and lexical cohesion in their texts.

From the findings, it can be claimed that Thai undergraduate writers tends to rely on lexical reiteration, conjunction, and reference to make their texts coherent. This practice is in line with English students from other nationalities and first language backgrounds. However, the use of such devices does not reflect the quality of the writing since only few pieces of writing were rated as competent. Moreover, the quality of the writing seems to depend upon the length of the text. That, in turn, requires attention to cohesion. If students write a longer text, containing more words, they tend to employ more cohesive devices in their texts, and thus yield a better quality of writing. To achieve a higher writing score, students cannot only rely on the numbers of cohesive devices but they have to consider proper cohesion in both lexical and clausal levels. Although the use of reiteration and reference seems appropriate to make the reader refer back and forth to the noun and process types in the text, different clauses, or even paragraphs need a signpost, or a cohesive device, that strings the text together.

\section{CONCLUSION}

As cohesion and coherence become prominent in order to produce a good text. Student writers need to understand how to employ these devices to make their text cohere around the central idea of the text. This study aimed to explore the common cohesive devices used in the writing development of Thai undergraduate students majoring in English. The frequency of cohesive devices was counted from student's writing. In addition, the study also wanted to examine whether there is a relationship between the frequency of cohesive devices used in the text and the text quality as rated by writing experts. The frequency of the cohesive devices used in the text was counted manually. The number of cohesive devices found in the corpus was validated by the AntConc program. Frequency, percentage, and a one-way ANOVA were used to identify the different cohesive devices in the students' text, while a Pearson correlation product of moment was employed to identify the relationship between number and types of cohesive devices used and the holistic quality of the texts. The findings revealed that student writers preferred to use reiteration, reference, conjunction, 
and ellipsis in their text. Reiteration was the dominant type of cohesive device found in the students' writing. In addition, a positive relationship between the number of words in the writing, the number of certain types of cohesive devices in the academic text, and the text quality was found.

From this study, it is suggested that writing teachers need to provide Thai EFL students a variety of cohesive tools that could enhance their written production. Moreover, teachers may recommend students to study how native speakers or competent writers progress their texts while staying focused on the central idea through the use of different cohesive devices. With the writing model and through series of practice, student writers may eventually produce more effective production through an understanding of cohesive devices in making their texts coherent and comprehensible.

\section{REFERENCES}

[1] Alarcon, B. J. \& Morales, K. N. S. (2011). Grammatical cohesion in students' argumentative essay. Journal of English and Literature, 2(5), 114-127.

[2] Biber, D., Conrad, S., \& Leech, G. (2002). Longman student grammar of spoken and written English. Essex, UK: Pearson Education.

[3] Centre for Educational Research and Innovation. (2007). Understanding the brain: The birth of a learning science. France: OCED Publishing.

[4] Chanyoo, N. (2013). A corpus-based study of connectors and thematic progression in the academic writing of Thai EFL students. Doctoral Dissertation. University of Pittsburgh, USA.

[5] Connor, J. U. A. (1990). Coherence: Research and pedagogical perspectives. Washington, DC: TESOL.

[6] Coskun, E. (2011). Cohesion compositions of Turkish and immigrant students. Educational Science: Theory and Practice, 11(1), 892-899.

[7] Crossley, S. A., \& McNamara, D. S. (2010). Cohesion, coherence and expert evaluation of writing proficiency. Conference proceedings at the 32nd annual conference of Cognitive Science Society.

[8] Crossley, S. A., Kyle, K., \& McNamara, D. S. (2016). The development and use of cohesive devices in L2 writing and their relations to judgments of essay quality. Journal of Second Language Writing, 32, 1-16.

[9] Diane, P., Odendahl, N., Quinlan, T., Fowles, M., Welsh, C., \& Bivens-Tatum, J. (2008). Cognitive models of writing: Writing proficiency as a complex integrated skill. Princeton, NJ: ETS.

[10] Field, Y. \& Oi, Y. L. M. (1992). A comparison of internal conjunctive cohesion in the English essay writing of Cantonese speakers and native speakers of English. RELC Journal, 23, 15-28.

[11] Fontaine, L. (2012). Analysing English grammar. London: Cambridge University Press.

[12] Halliday, M. A. K. \& Hasan, R. (1976). Cohesion in English. New York, NY: Routledge.

[13] Hogue, A., \& Oshima, A. (2007). Introduction to academic writing (3rd ed.). White Plains: Pearson.

[14] Johnson, P. (1992). Cohesion and coherence in compositions in Malay and English. RELC Journal, 23(2), 1-17.

[15] Kellogg, R. T. (2008). Training writing skills: A cognitive development perspective. Journal of Writing Research, 1(1), 1-26.

[16] Liu, M. \& Briane, G. (2005). Cohesive features in argumentative writing produced by Chinese undergraduate. System, 33 (4), 623-636.

[17] Mahlberg, M. (2006). Lexical cohesion: Corpus linguistic theory and its application in English language teaching. International Journal of Corpus Linguistics, 11(3), 363-383.

[18] Mei, W. S. (2006). Creating constructive rhetorical stance: Investigating the strategy of problematization in students' argumentation. RELC Journal, 37(3), 329-353.

[19] Meisuo, Z. (2000). Cohesive features in the expository writing of undergraduates in two Chinese universities. RELC Journal, 31(1), 61-95.

[20] Palmer, J. (1999). Coherence and cohesion in the language classroom: the use of lexical reiteration and pronominalisation. RELC Journal, 30(6), 61-85.

[21] Rao, Z. (2007). Training in brainstorming and developing writing skills. ELT Journal, 61(2), 100-106.

[22] Thompson, G. (1996). Introducing functional grammar (2nd ed.). London: Hodder Education.

[23] Yang, W. \& Sun, Y. (2012). The use of cohesive devices in argumentative writing by Chinese EFL learners at different proficiency levels. Linguistics and Education, 23, 31-48.

Natthapong Chanyoo is currently a Director of the MA Program in Applied Linguistics at the Faculty of Liberal Arts, Mahidol University. He received a PhD in Instruction and Learning with concentrations on English Education and Applied Linguistics from University of Pittsburgh, USA. His research interests include TEFL, Systemic Functional Linguistics, and Psychology of Foreign Language Learning. He may be reached at natthapong [dot]cha[add]mahidol.edu. 